\title{
Involvement of Salicylate and Jasmonate Signaling Pathways in Arabidopsis Interaction with Fusarium graminearum
}

\author{
Ragiba Makandar, ${ }^{1,2}$ Vamsi Nalam, ${ }^{1}$ Ratnesh Chaturvedi, ${ }^{1}$ Richard Jeannotte, ${ }^{3}$ Alexis A. Sparks, ${ }^{3}$ and \\ Jyoti Shah ${ }^{1}$ \\ ${ }^{1}$ Department of Biological Sciences, University of North Texas, Denton, TX 76203, U.S.A.; ${ }^{2}$ Department of Plant Sciences, \\ University of Hyderabad, Gachibowli, Hyderabad, India; ${ }^{3}$ Kansas Lipidomics Research Center, Division of Biology, Kansas \\ State University, Manhattan, KS 66506, U.S.A.
}

Submitted 17 February 2010. Accepted 20 March 2010.

Fusarium graminearum is the principal causative agent of Fusarium head blight (FHB), a devastating disease of wheat and barley. This fungus can also colonize Arabidopsis thaliana. Disease resistance was enhanced in transgenic wheat and Arabidopsis plants that constitutively overexpress the NONEXPRESSOR OF PATHOGENESIS-RELATED GENES 1 (NPRI) gene, which regulates salicylic acid (SA) signaling and modulates the activation of jasmonic acid (JA)-dependent defenses. Here, we provide several lines of evidence that reveal an important role for $\mathrm{SA}$ and JA signaling in Arabidopsis defense against $F$. graminearum. SA level was elevated in fungus-inoculated leaves, and SA application and biologically activated systemic acquired resistance enhanced resistance. Furthermore, the disruption of SA accumulation and signaling in the sid 2 mutant and NahG transgenic plant, and the npr1 and wrky18 mutants, respectively, resulted in heightened susceptibility to this fungus in leaves and inflorescence. JA signaling was activated in parallel with $\mathrm{SA}$ signaling in the fungus-challenged plants. However, the hyperresistance of the JA pathway mutants opr3, coil, and jarl indicates that this pathway contributes to susceptibility. Genetic and biochemical experiments indicate that the JA pathway promotes disease by attenuating the activation of $\mathrm{SA}$ signaling in fungusinoculated plants. However, the hypersusceptibility of the jar1 npr1 double mutant compared with the nprl mutant suggests that $J A R I$ also contributes to defense, signifying a dichotomous role of JA and a $J A R I$-dependent mechanism in this interaction.

Plants have evolved a multitude of defense mechanisms to control diseases. These include preformed mechanisms, such as the physical barrier provided by the cell wall and cuticle, as well as inducible mechanisms. Pathogen attack induces expression of numerous defense-related genes; for example, the pathogenesis-related $(P R)$ genes, some of which encode antimicrobial proteins (van Loon et al. 2006). Expression of these genes in pathogen-challenged plants is regulated by a variety of mechanisms, including those dependent on the sig-

Corresponding author: Jyoti Shah; E-mail: shah@unt.edu; Telephone: +1.940 .565 .3535 ; Fax: +1.940.565.4136.

* The $\boldsymbol{e}$-Xtra logo stands for "electronic extra" and indicates that one supplementary figure is published online. naling molecules salicylic acid (SA) and jasmonic acid (JA). However, the overall effectiveness of one or more of these responses in controlling disease depends on the lifestyle of the pathogen (Glazebrook 2005; Wasternack 2007). Necrotrophic pathogens derive their nutrients from dead host cells while biotrophs derive nutrients from live host cells. Some pathogens (hemibiotrophs) display both biotrophic and necrotrophic phases of growth.

JA is an important regulator of plant defenses against pathogens that display necrotrophy. The role of JA in plant defense has been extensively reviewed (Glazebrook 2005; Wasternack 2007). Exogenously applied methyl-JA (MJ) enhanced Arabidopsis thaliana resistance to several necrotrophic fungi (Thomma et al. 2000). In contrast, the Arabidopsis fad3 fad7 fad 8 triple mutant, which is deficient in JA, exhibits enhanced susceptibility to Pythium irregulare (Staswick et al. 1998). Similarly, compared with the wild-type (WT) plant, resistance against $P$. irregulare and the soft-rot-causing fungus Botrytis cinerea was compromised in the Arabidopsis jasmonate resistant 1 (jarl) mutant (Ferrari et al. 2003; Staswick et al. 1998), which is insensitive to JA due to its inability to synthesize JAisoleucine (Ile) (Staswick and Tiryaki 2004). Resistance to $B$. cinerea was also compromised in the JA-insensitive coronatine insensitive 1 (coil) mutant (Thomma et al. 1998). JA signaling is also critical for controlling black spot disease caused by Alternaria brassicicola (Thomma et al. 1998).

SA signaling primarily impacts plant defense against pathogens that exhibit a biotrophic phase in their life cycle (Glazebrook 2005). The role of SA in plant defense has been widely studied in Arabidopsis (Durrant and Dong 2004; Chaturvedi and Shah 2007). The NONEXPRESSOR OF PR GENES 1 (NPRl) gene is a key regulator of SA signaling in Arabidopsis. Loss of NPR1 activity in nprl mutant plants is accompanied by the attenuation of SA-dependent defenses, resulting in heightened susceptibility to the oomycete pathogen Hyaloperonospora arabidopsidis, the fungal pathogen Erysiphe orontii, and the hemibiotrophic bacterial pathogen Pseudomonas syringae (Cao et al. 1994; Delaney et al. 1995; Shah et al. 1997; Reuber et al. 1998). In contrast, overexpression of NPRI enhances sensitivity to SA and resistance against these pathogens. The NPR 1 protein regulates the activity of a family of bZIP transcription factors, resulting in the expression of defense genes. NPR1 also modulates the expression of genes involved in secretion of defense proteins to the apoplast (Wang et al. 2005). Gene expression studies indicated that the WRKY18encoded transcription factor is required for a subset of NPRI- 
directed functions (Chen and Chen 2002; Wang et al. 2006; Xu et al. 2006).

In addition to basal defenses, $\mathrm{SA}$ and NPRI also are required for the manifestation of systemic acquired resistance (SAR), an inducible defense mechanism that confers resistance against a broad spectrum of pathogens (Métraux et al. 2002; Durrant and Dong 2004; Chaturvedi and Shah 2007). SAR is activated in the uninfected parts of a plant in response to an infection elsewhere in the plant. Another inducible defense mechanism that involves NPRl is induced systemic resistance (ISR), which is stimulated by root colonizing rhizobacteria (Pieterse and van Loon 2004). In Arabidopsis, ISR confers heightened resistance to Fusarium oxysporum and $P$. syringae. Activation of ISR requires JA signaling. However, SA is not required for ISR (Pieterse and van Loon 2004). Although JA and NPR1 cooperate, leading to the activation of ISR, JA can also antagonize signaling through NPRI under other conditions (Koornneef and Pieterse 2008). For example, activation of JA signaling marginalizes SA accumulation and downstream signaling through NPRl in $P$. syringae-infected Arabidopsis leaves (Kloek et al. 2001; Spoel et al. 2003).

Fungi in the genus Fusarium are ubiquitously distributed in terrestrial environments. Several Fusarium spp. are important phytopathogens. F. graminearum Schwabe (teleomorph Gibberella zeae (Schwein.) Petch) causes Fusarium head blight (FHB), seedling blight, and root rot in cereal crops (Bai and Shaner 2004; Goswami and Kistler 2004; Agrios 2005; Walter et al. 2010). Monogenic, gene-for-gene resistance to $F$. graminearum has not been identified. In cultivated wheat, the best source of resistance to FHB, which is controlled by several complex quantitative loci, is the Chinese cv. Sumai 3 (Bai and Shaner 2004). However, Sumai 3-derived resistance is insufficient to control damage under high disease pressure. Other problems associated with using Sumai 3 as a source of resistance include increased shattering and susceptibility to other diseases. F. graminearum can enter the host through stomates or directly penetrate the host surface. The fungus secretes an array of hydrolases that could facilitate penetration (Walter et al. 2010). Like most Fusarium spp., necrotrophy is accompanied by increase in vigor of colonization by $F$. graminearum. However, there is a brief biotrophic phase during the early stages of infection when $F$. graminearum does not penetrate host cells and exhibits extracellular growth (Goswami and Kistler 2004).

Despite the damaging potential of this fungus, our understanding of plant defense mechanisms against this pathogen is very limited. A recent study demonstrated that FHB resistance in wheat was enhanced by application of $\mathrm{MJ}(\mathrm{Li}$ and $\mathrm{Yen}$ 2008). However, whether plants utilize JA signaling to control $F$. graminearum infection is not known. Relying on transcriptome analysis, the above study also suggested that ethylene signaling likely contributes to FHB resistance. However, genetic studies indicated otherwise. Attenuation of ethylene signaling in wheat resulted in hyperresistance, suggesting that ethylene signaling contributes to susceptibility (Chen et al. 2009). Fungal infection of wheat spikes also resulted in systemic expression of a subset of $P R$ genes (Pritsch et al. 2001). However, whether this systemic induction of $P R$ genes contributes to controlling spread of the fungus from one spikelet to another is not known. Moreover, benzothiadiazole [benzo $(1,2,3)$ thiadiazole-7-carbothioic acid $S$-methyl ester] (BTH), a functional analog of SA, when locally applied to wheat heads, did not enhance FHB resistance (Yu and Muehlbauer 2001). Hence, it was suggested that SA signaling is unlikely to contribute to host resistance to FHB (Yu and Muehlbauer 2001; Walter et al. 2010). However, FHB resistance in wheat was enhanced by application of a SAR-inducing activity extracted from Arabidopsis (Chaturvedi et al. 2008) and by the constitutive overexpression
(OE) of NPRl (Makandar et al. 2006). Furthermore, this enhanced resistance to $F$. graminearum was accompanied by increased sensitivity to BTH, and the faster and stronger expression of PRI in the fungus-challenged spikes of NPRl(OE) wheat, than in nontransgenic plants (Makandar et al. 2006). These results suggest that SA signaling may have a function in wheat defense against $F$. graminearum. It is equally likely that the $N P R l(\mathrm{OE})$-conferred resistance to $F$. graminearum is due to a mechanism or mechanisms other than that involving SA. As mentioned above, NPR1 also participates in defenses that are not dependent on SA. Molecular-genetic approaches are needed to further characterize the role of these signaling mechanisms in plant defense and susceptibility to $F$. graminearum. However, these are difficult to conduct in wheat due to the limited availability of molecular-genetic tools.

$F$. graminearum has been shown to colonize and cause disease in Arabidopsis. Inoculation of Arabidopsis inflorescence with $F$. graminearum resulted in fungal growth and disease in floral tissues and spread of the fungus to the developing siliques and seed (Urban et al. 2002; Cuzick et al. 2008). In contrast, when fungal spores were placed on the leaf surface, although they germinated and the hyphae branched, penetration of the leaf was poor (Chen et al. 2006). However, wounding of the leaves promoted infection by the fungus and subsequent spread to other organs (Chen et al. 2006). Efficient infection and disease also occurs when the fungus is infiltrated into Arabidopsis leaves, thereby avoiding barriers provided by the leaf surface (Makandar et al. 2006) (Fig. 1A to C). Several other studies also have demonstrated that Arabidopsis is an amenable host for characterizing host mechanisms that contribute to resistance and susceptibility to $F$. graminearum (Skadsen and Hohn 2004; Van Hemelrijck et al. 2006; Savitch et al. 2007; Chen et al. 2009).

In this study, we have evaluated the involvement of SA and JA signaling in the interaction between Arabidopsis and $F$. graminearum. We provide multiple lines of evidence that Arabidopsis engages SA signaling through NPRl to control disease. In contrast, JA signaling has a dichotomous role in this interaction. On the one hand, JA signaling promotes disease by constraining the activation of SA- and NPRI-regulated defenses. On the other hand, JA signaling promotes overall resistance to $F$. graminearum by participating in an NPRIindependent mechanism.

\section{RESULTS}

\section{Activation of SAR reduces $F$. graminearum disease severity in Arabidopsis.}

Constitutive expression of NPRl, which is a key regulator of SAR, enhances resistance against $F$. graminearum in Arabidopsis (Makandar et al. 2006); therefore, we tested whether the biological activation of SAR with an avirulent (Avr) strain of $P$. syringae pv. tomato could reduce the severity of disease caused by $F$. graminearum. Fungal disease severity was lower in plants in which SAR was activated (Avr P. syringae pv. tomato) than in control plants not exhibiting SAR (Mock) (Fig. 2). Activation of SAR requires the translocation of a factor from the Avr pathogen-inoculated leaf to the distal leaves. This SAR-activating factor is present in petiole exudates $(\mathrm{PeX})$ collected from the Avr pathogen-inoculated leaves but not in PeX collected from mockinoculated leaves (Chaturvedi et al. 2008). The efficacy of SAR in protecting Arabidopsis against $F$. graminearum was further evaluated by testing the ability of Avr PeX, when applied to the lower leaves, to protect the upper leaves against $F$. graminearum. Compared with the Mock PeX-treated plants, Avr PeX, when applied to WT plants, enhanced resistance against F. graminearum in the upper leaves (Fig. 2). Taken together, 
the above results confirm that, in Arabidopsis, SAR can reduce the severity of disease caused by $F$. graminearum.

SA signaling is activated

in $\boldsymbol{F}$. graminearum-challenged plants.

To determine whether SA-mediated defenses are engaged by Arabidopsis when infected with $F$. graminearum, SA content

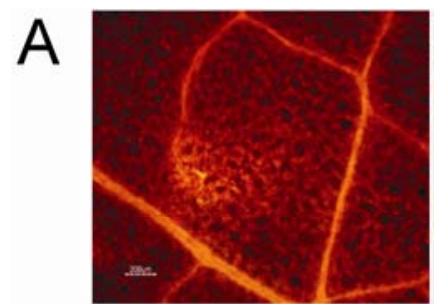

Mock-inoculated

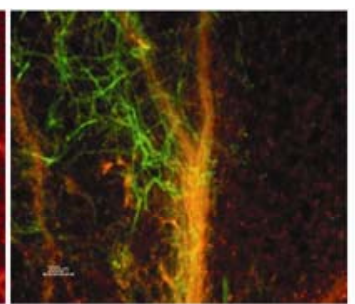

F. graminearum-inoculated
B
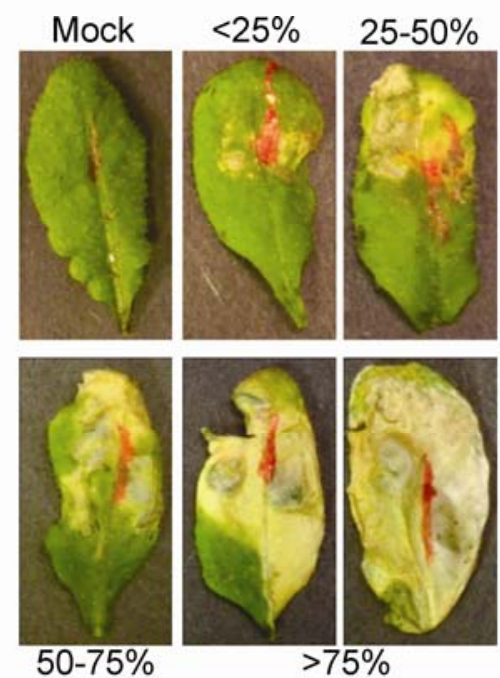

C
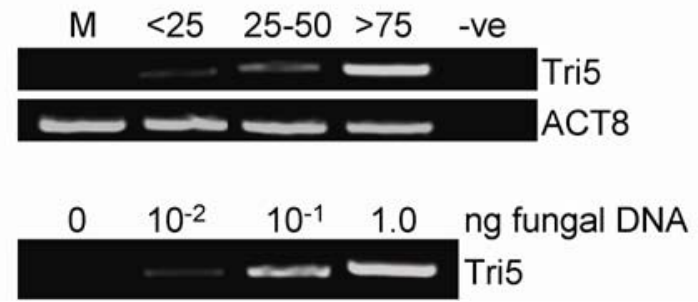

Fig. 1. Fusarium graminearum infection of Arabidopsis leaves. A, Colonization of Arabidopsis accession Columbia leaves by $F$. graminearum. Plant cells fluoresce red due to binding of Toluidine blue-O and fungal hyphae fluoresce green due to binding of the chitin specific WGA-Alexa Fluor 488. A mock-inoculated leaf provided the negative control for fluorescence emitted from fungal mass. B, Disease symptoms in $F$. graminearum-infected Arabidopsis leaves. Diseased leaves are grouped into four classes ( $<25,25$ to 50,50 to 75 , and $>75 \%$ chlorosis) based on the percentage of leaf area showing chlorosis relative to the mock-inoculated leaf. C, Top panel: polymerase chain reaction (PCR) analysis of $F$. graminearum Tri5 gene to monitor fungal growth in Arabidopsis leaves exhibiting different levels of chlorosis. PCR analysis for the Arabidopsis ACT8 gene provided a positive control for DNA quality, DNA extracted from mock (M)-inoculated leaves provided a negative control for Tri5 amplification, and PCR reactions lacking plant and fungal DNA (-ve) provided a negative control for PCR. PCR conducted with fungal DNA isolated from $F$. graminearum cultivated on synthetic medium was used for determining the relative abundance of fungal DNA in leaf samples. Leaves infiltrated with a suspension lacking fungus provided the mock control. These experiments were conducted two times. and expression of the SA-inducible $P R 1$ gene were monitored in F. graminearum-inoculated leaves of WT Arabidopsis. Compared with the mock-inoculated leaves, $F$. graminearum inoculation resulted in an increase in SA content and $P R l$ transcript level in the WT plant (Fig. 3A and B). Fungal inoculation-induced accumulation of $P R l$ transcript was attenuated in the SA biosynthesis mutant sid2, which lacks isochorismate synthase activity that is required for SA synthesis, and the NahG transgenic, which expresses an SA-degrading salicylate hydroxylase. PRI expression was also lower in the leaves of the fungus-inoculated nprl mutant than in the corresponding WT plant (Fig. 3B). These results confirm that SA-dependent signaling is activated in Arabidopsis leaves inoculated with $F$. graminearum.

\section{Activation of SA signaling reduces}

F. graminearum disease severity in Arabidopsis leaves.

SA signaling is constitutively active in the Arabidopsis cpr 5 and ssi 2 mutants. Both of these well-characterized mutants constitutively express the PRI gene and accumulate high levels of SA (Fig. 3B) (Bowling et al. 1994; Shah et al. 2001). Disease severity was lower in $F$. graminearum-inoculated leaves of the Arabidopsis cpr 5 and ssi 2 mutants than the WT plant (Fig. 4A). Disease severity was also lower on plants that were pretreated with SA and BTH (Fig. 4B). These results, along with the ability of biologically activated SAR to enhance resistance against $F$. graminearum, suggested that SA may have an important role in controlling the severity of disease caused by $F$. graminearum. However, it should be noted that along with SA, JA signaling is also hyperactive in the cpr5 mutant (Bowling et al. 1994; Jing et al. 2007) and could potentially influence the interaction between $\operatorname{cpr} 5$ and $F$. graminearum. To further test the involvement of SA signaling in controlling $F$. graminearum infection, disease severity was compared be-
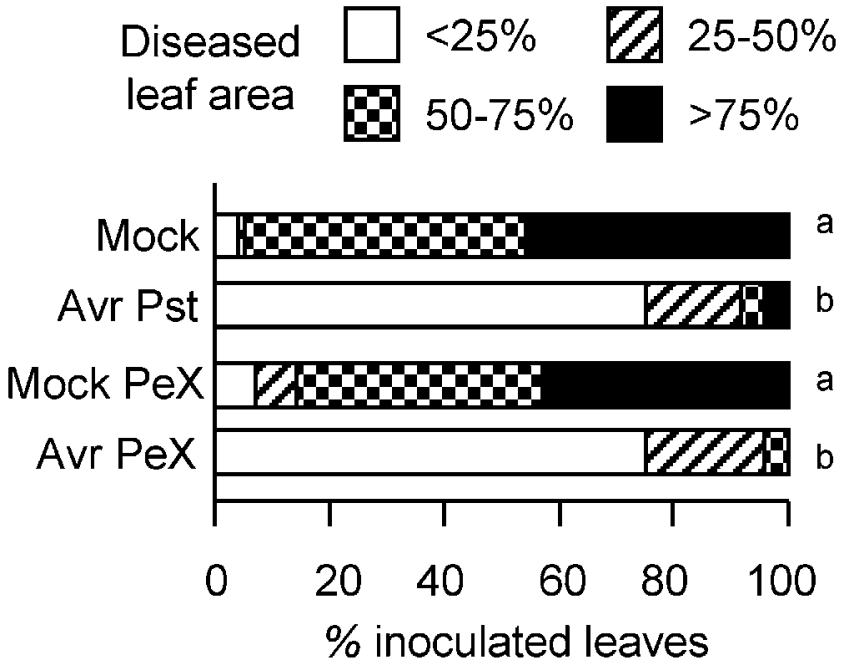

Fig. 2. Systemic acquired resistance (SAR) confers protection against Fusarium graminearum in Arabidopsis. F. graminearum disease severity, 4 days postinoculation, in leaves of wild-type accession Columbia plants in which SAR had been activated by infiltration of three lower leaves with an avirulent strain of Pseudomonas syringae pv. tomato DC3000 (Avr Pst) or petiole exudates (PeX) collected from Avr P. syringae pv. tomato-inoculated Col leaves (Avr PeX). Plants that were pretreated with $10 \mathrm{mM} \mathrm{MgCl}{ }_{2}$ (Mock) or PeX collected from $10 \mathrm{mM}$ $\mathrm{MgCl}_{2}$-infiltrated Columbia leaves (Mock PeX) provided controls for this experiment. Fractions of inoculated leaves exhibiting necrosis covering $<25,25$ to 50,50 to 75 , and $>75 \%$ of the leaf area were determined for each treatment. Different letters next to the bars indicate values that are significantly different $(P<0.05)$ from each other. These experiments were repeated three times. 
tween $F$. graminearum-inoculated WT and the sid2 mutant plant. A transgenic line, $N P R 1(\mathrm{OE})$, that constitutively overexpresses NPR1 from the Cauliflower mosaic virus $35 \mathrm{~S}$ promoter and exhibits heightened resistance to $F$. graminearum (Makandar et al. 2006), was used as a resistant control. Disease severity was higher in the sid2 mutant plant than in the WT and NPRl(OE) plants (Fig. 4A). Similarly, disease severity was also higher in the NahG transgenic and nprl mutant plant than in the corresponding WT plants (Fig. 4A). Also, NPRl was required for the SA- and BTH-conferred heightened resistance against $F$. graminearum (Fig. 4B). Similar to the NPRl(OE) plants, overexpression of WRKY18, which mediates a subset of NPRI-directed functions (Chen and Chen 2002; Wang et al. 2006; $\mathrm{Xu}$ et al. 2006), enhanced resistance to $F$.

A

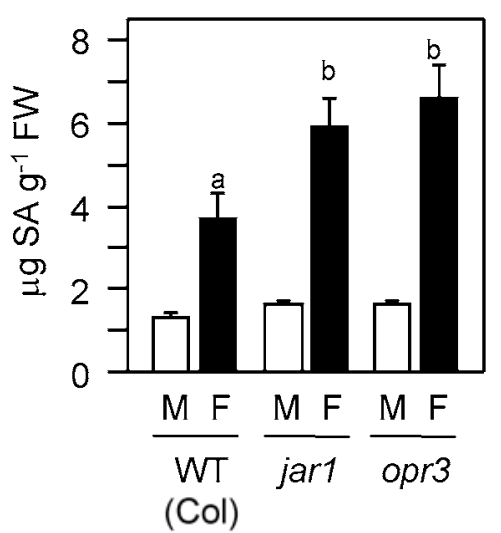

B
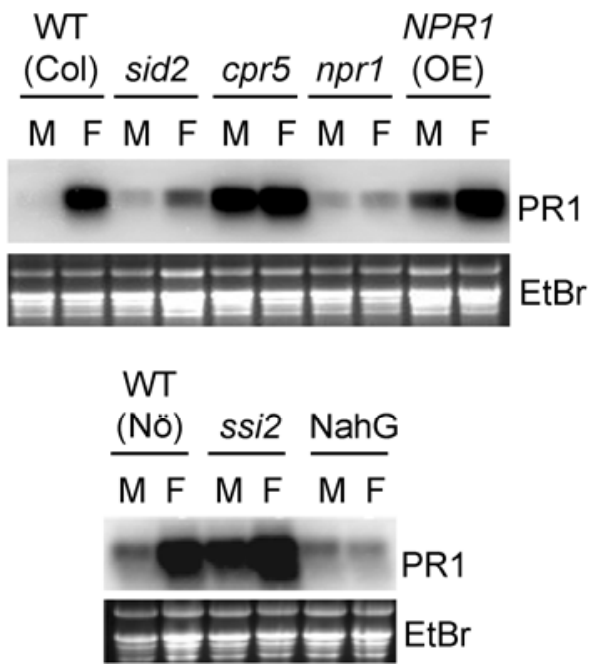

Fig. 3. Salicylic acid (SA) signaling is activated in Fusarium graminearum-inoculated Arabidopsis leaves. A, Total salicylate content (SA + SAglucoside) in mock (M)- and $F$. graminearum-inoculated (F) leaves of wild-type (WT) Arabidopsis accession Columbia (Col) and the jarl and opr 3 mutant plants. Leaves for SA quantification were harvested $24 \mathrm{~h}$ postinoculation (hpi). Each bar represents the average SA content \pm standard deviation from five replications per treatment. Different letters next to the bars indicate values that are significantly different $(P<0.05)$ from each other. This experiment was repeated two times. B, $P R 1$ expression in F. graminearum-challenged Arabidopsis leaves. PR1 transcript accumulation was monitored by Northern blot analysis of RNA isolated 24 hpi from mock (M)- and F. graminearum-inoculated (F) Arabidopsis leaves. A ${ }^{32} \mathrm{P}$ labeled $P R 1$ gene-specific probe was used to monitor $P R 1$ transcript accumulation and ethidium bromide $(\mathrm{EtBr})$ staining was used to monitor quality of RNA and gel loading. Top panel: PRl expression in WT accession Columbia (Col); the sid2, cpr5, and nprl mutants; and NPRI(OE) transgenic plant. Bottom panel: PRl expression in WT accession Nössen (Nö), the ssi 2 mutant, and NahG transgenic plant. These experiments were repeated three times. Leaves infiltrated with a suspension lacking fungus provided the mock control. graminearum in the WRKY18(OE) plant (Fig. 4A). Conversely, compared with the WT, loss of WRKY18 function in the wrky 18 mutant resulted in higher severity of infection (Fig. 4A). Together, the above results confirm the importance of SA and NPR 1 -dependent signaling in controlling F. graminearum disease severity in Arabidopsis leaves.

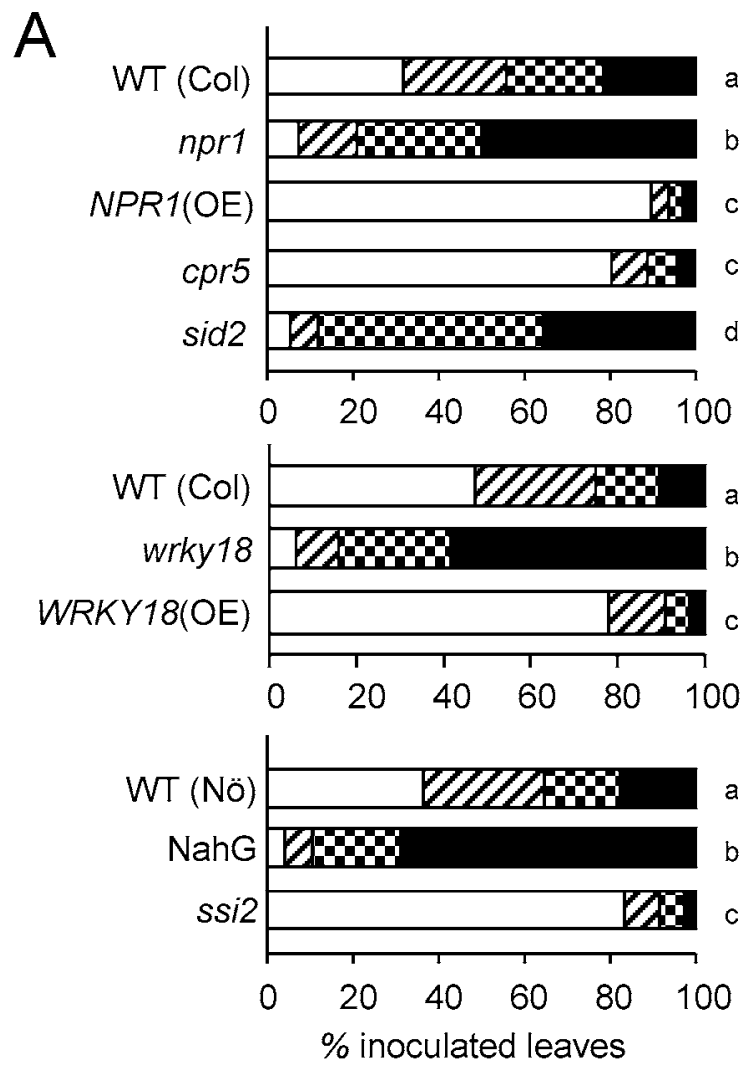

B

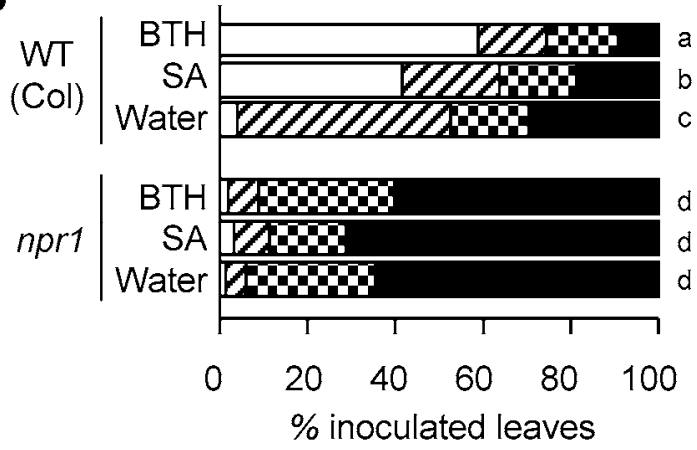

Fig. 4. Defects in salicylic acid (SA) synthesis and signaling impact Fusarium graminearum disease severity in Arabidopsis leaves. A, Top panel: disease severity in wild-type (WT) Arabidopsis accession Columbia $(\mathrm{Col})$ and the $n p r l, c p r 5$, sid2, and $N P R l(\mathrm{OE})$ transgenic plant at 4 days postinoculation (dpi). Middle panel: disease severity in WT (Col), the wrky 18 mutant, and the WRKY18(OE) transgenic plant at 4 dpi. Bottom panel: disease severity in WT Arabidopsis accession Nössen (Nö), the NahG transgenic, and ssi 2 mutant plant at 4 dpi. The three panels are derived from separate experiments. B, F. graminearum disease severity in leaves of WT $(\mathrm{Col})$ and $n p r l$ mutant plants that were previously treated with a $200-\mu \mathrm{M}$ solution of SA and benzothiadiazole [benzo $(1,2,3)$ thiadiazole-7-carbothioic acid $S$-methyl ester] to induce systemic acquired resistance. Plants pretreated with water provided controls for this experiment. Fractions of inoculated leaves exhibiting necrosis covering $<25,25$ to 50,50 to 75 , and $>75 \%$ of the leaf area were determined for each treatment. Different letters next to the bars indicate values that are significantly different $(P<0.05)$ from each other. Experiments were repeated three times. 
SA signaling controls $\boldsymbol{F}$. graminearum disease severity in Arabidopsis inflorescence.

Because $F$. graminearum infects floral tissues of wheat and barley, we also compared susceptibility of Arabidopsis inflorescence in SA biosynthesis and signaling mutants. Inflorescence infection ratings (Fusarium-Arabidopsis disease [FAD] score) were determined as previously described (Urban et al. 2002). Compared with the WT plants, the FAD score was higher on inflorescence tissue of the sid2, nprl, and wrkyl8 mutants, suggesting heightened disease susceptibility (Table 1). Disease susceptibility was also elevated in NahG inflorescence. In contrast, FAD scores were lower in the ssi2, cpr5, $N P R l(\mathrm{OE})$, and WRKYl8(OE) plants, indicating heightened resistance. Based on these results, we conclude that, similar to the leaf tissue, SA signaling through NPRI also is important for limiting severity of disease caused by $F$. graminearum in Arabidopsis inflorescence.

\section{JA signaling attenuates SA signaling}

to promote $F$. graminearum disease severity.

$F$. graminearum infection resulted in elevated expression of the PDF1.2 gene (Fig. 5A), which is a molecular marker for the activation of JA signaling. PDF1.2 expression paralleled the expression of $P R I$. Because JA contributes to plant defense against necrotrophic fungi, we tested whether severity of disease caused by $F$. graminearum was limited by MJ application.
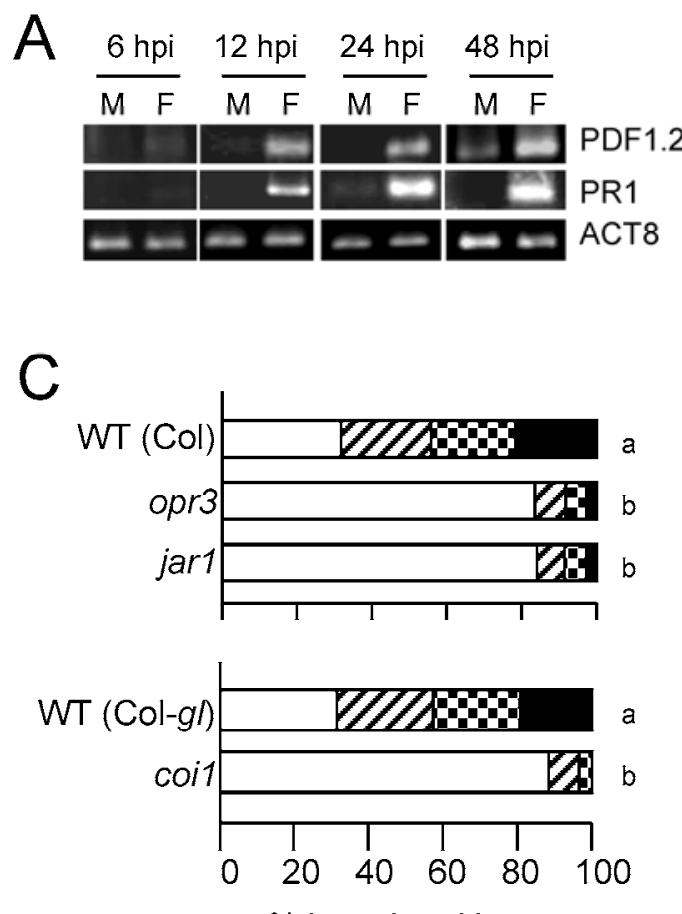

$\%$ inoculated leaves
B Chemical

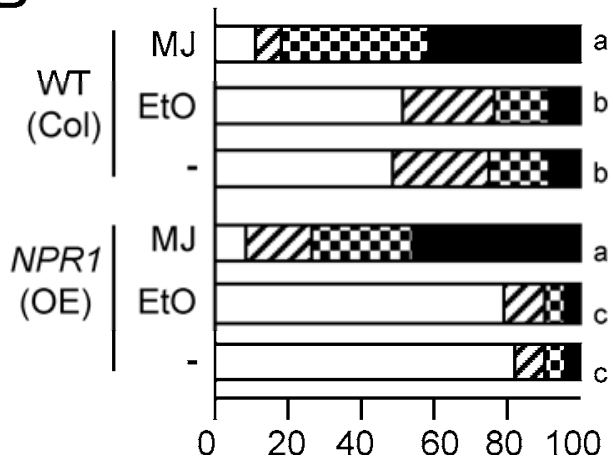

$\%$ inoculated leaves
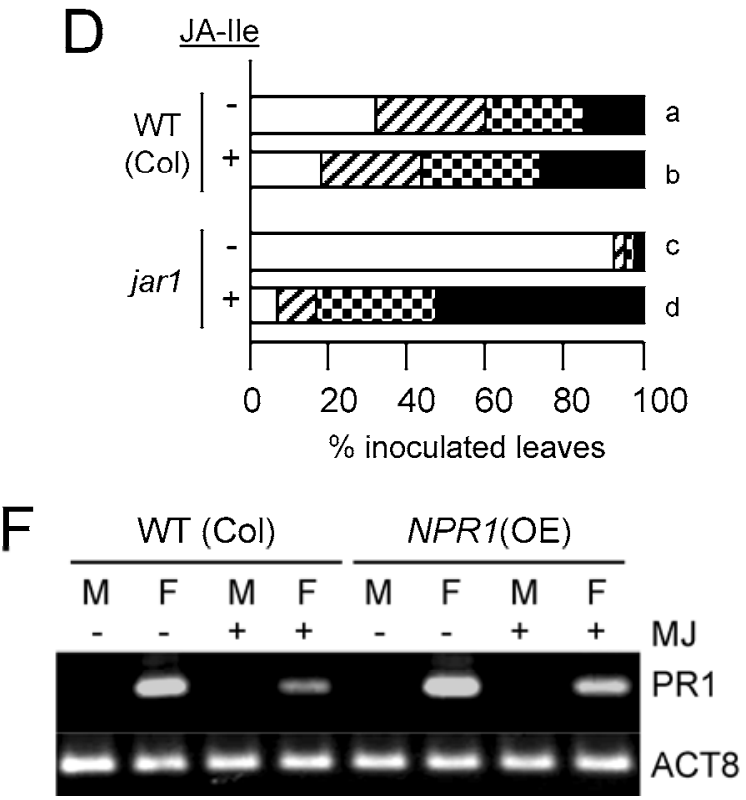

Fig. 5. Jasmonic acid (JA) signaling attenuates the activation of salicylic acid (SA) signaling in Fusarium graminearum-challenged plants. A, Reverse-transcription polymerase chain reaction (RT-PCR) analysis of PDF1.2 and PR1 expression in leaves of wild-type (WT) accession Columbia plants at 6, 12, 24, and $48 \mathrm{~h}$ postinoculation (hpi) with F. graminearum (F). RNA extracted from mock (M)-inoculated plants provided the negative control. B, $F$. graminearum disease severity in leaves of WT accession Col and the NPRl(OE) transgenic plant that were exposed to methyl-JA (MJ) vapors $24 \mathrm{~h}$ prior to fungal inoculation. Plants that were exposed to ethanol, which was used as a solvent for MJ, and plants that did not receive any chemical treatment provided the controls for this experiment. C, Top panel: F. graminearum disease severity in WT Arabidopsis accession Columbia (Col) and the opr3 and jarl mutant. Lower panel: F. graminearum disease severity in WT accession Columbia-glabra (Col-gl) and the coil mutant. D, F. graminearum disease severity in WT accession Columbia (Col) and the jarl mutant plants that were infiltrated with a 200- $\mu \mathrm{M}$ solution of JA-isoleucine (JA-Ile) $24 \mathrm{~h}$ prior to fungal inoculation. Plants treated with water provided the controls. E, RT-PCR analysis of PRI expression in mock (M)- and F. graminearum (F)-inoculated WT Arabidopsis accession Columbia (Col) and the jarl and opr3 mutant plants. Leaves for RT-PCR analysis were harvested 24 hpi. F, RT-PCR analysis of PR1 expression in mock (M)and $F$. graminearum $(\mathrm{F})$-inoculated WT $(\mathrm{Col})$ and the $N P R l(\mathrm{OE})$ transgenic plants that were exposed to MJ vapors $24 \mathrm{~h}$ prior to fungal inoculation. Plants that were exposed to ethanol vapors provided the controls for this experiment. In A, E, and F, ACT8 expression served as a control for RNA quality. In B, C, and D, disease severity was scored 4 days postinoculation. Fractions of inoculated leaves exhibiting necrosis covering $<25,25$ to 50,50 to 75 , and $>75 \%$ of the leaf area were determined for each treatment. Different letters next to the bars indicate values that are significantly different $(P<0.05)$ from each other. In $\mathrm{A}, \mathrm{E}$, and $\mathrm{F}$, leaves infiltrated with a suspension lacking fungus provided the mock control. Experiments in $\mathrm{B}, \mathrm{C}$, and $\mathrm{E}$ were repeated three times and those in $\mathrm{A}, \mathrm{D}$, and $\mathrm{F}$ were repeated two times. 
Quite to the contrary, compared with the untreated and ethanol-treated plants, pretreatment with MJ enhanced disease severity in WT Arabidopsis (Fig. 5B). JA's role in Arabidopsis interaction with $F$. graminearum was further characterized by evaluating disease severity in the JA biosynthesis mutant, opr3, and the JA signaling mutants, jarl and coil. Compared with the WT plant, disease severity was lower in leaves of the opr3, jarl, and coil mutants (Fig. 5C). Similarly, compared with the WT, disease severity was lower in the inflorescence of the opr3 and jarl mutants (Table 1). Application of JA-Ile, a product of the JARl-encoded enzyme, restored disease severity in the jarl mutant (Fig. 5D), thus confirming that signaling through JARl contributes to disease severity.

SA content and PRI transcript accumulation were higher in the $F$. graminearum-inoculated leaves of the opr 3 and jarl mutants than the WT plant (Figs. 3A and 5E), suggesting that the impact of JA signaling on promoting disease is likely due to the attenuation of SA signaling during Arabidopsis interaction with $F$. graminearum. In concurrence with this hypothesis, pretreatment with $\mathrm{MJ}$ attenuated the fungal infection-induced accumulation of $P R l$ transcript in WT and $N P R l(\mathrm{OE})$ plants (Fig. 5F) and the $N P R l(\mathrm{OE})$-conferred heightened resistance to $F$. graminearum (Fig. 5B). To test this hypothesis further, disease severity was evaluated in the jarl nprl double mutant plant. Presence of the nprl allele resulted in loss of the jarlconferred heightened resistance to $F$. graminearum in leaves

Table 1. Fusarium graminearum disease in Arabidopsis inflorescence

\begin{tabular}{lr}
\hline Genotype $^{\mathbf{a}}$ & \multicolumn{1}{c}{ FAD $^{\mathbf{b}}$} \\
\hline WT (Col) & $5.7 \pm 0.7$ \\
nprl & $12.0 \pm 1.2$ \\
NPRl(OE) & $1.5 \pm 0.2$ \\
cpr5 & $1.7 \pm 0.2$ \\
sid2 & $9.3 \pm 0.8$ \\
wrky18 & $12.7 \pm 1.4$ \\
WRKY18(OE) & $1.5 \pm 0.2$ \\
opr3 & $1.2 \pm 0.2$ \\
jarl & $1.8 \pm 0.2$ \\
WT (Nö) & $4.0 \pm 0.6$ \\
NahG & $16.3 \pm 2.2$ \\
ssi2 & $1.7 \pm 0.3$ \\
\hline
\end{tabular}

${ }^{\mathrm{a}} \mathrm{WT}=$ wild type and $\mathrm{OE}=$ overexpression

${ }^{\mathrm{b}}$ Fusarium-Arabidopsis disease (FAD) value was evaluated at 7 days postinoculation.

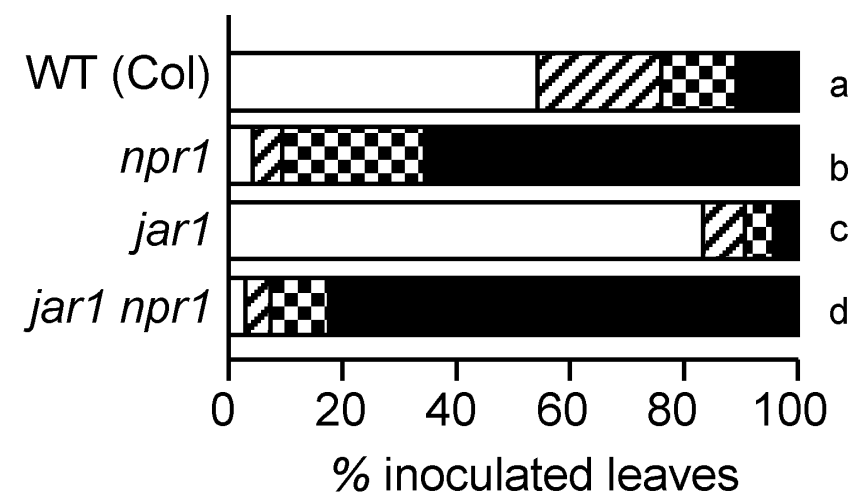

Fig. 6. $N P R 1$ is required for the jarl-conferred enhanced resistance to Fusarium graminearum. F. graminearum disease severity in leaves of wild-type (WT) Arabidopsis accession Columbia (Col) and the npr1, jar1, and jarl nprl double mutant plants at 4 days postinoculation. Fractions of inoculated leaves exhibiting necrosis covering $<25,25$ to 50,50 to 75 , and $>75 \%$ of the leaf area were determined for each treatment. Different letters next to the bars indicate values that are significantly different $(P<0.05)$ from each other. This experiment was repeated three times.
(Fig. 6). The jarl-conferred hyperresistance in inflorescence tissue was also dependent on the presence of the WT NPRI allele (Table 2).

\section{JA signaling contributes to resistance during later stages of infection.}

Progression of disease in leaves was faster and more severe on the jarl nprl double mutant than the nprl mutant (Fig. 6; Supplementary Fig. S1). Most of the jarl nprl plants had completely succumbed to disease by 3 days postinoculation (dpi), which is a few days earlier than the nprl mutant. Similarly, disease ratings in inflorescence tissue were higher for the jarl nprl double mutant than the nprl single mutant (Table 2). These results suggest that JARI contributes to overall resistance, as well, although its contribution was masked in the presence of NPRl. We further tested the involvement of JA signaling in Arabidopsis defense against $F$. graminearum by exposing plants inoculated with $F$. graminearum to MJ beginning at $0,6,12$, and $24 \mathrm{~h}$ postinoculation (hpi). Plants exposed to ethanol provided the control. Contrary to the enhanced disease severity observed in plants exposed to $\mathrm{MJ}$ at the beginning of the infection ( $0 \mathrm{hpi})$ and at $6 \mathrm{hpi}$, exposure to MJ at 12 and $24 \mathrm{hpi}$ enhanced resistance (Fig. 7). We conclude that, although JA signaling promotes $F$. graminearum disease by attenuating the activation of SA signaling, JA signaling also contributes to Arabidopsis defense, presumably during the later stages of infection.

Table 2. NONEXPRESSOR OF PATHOGENESIS-RELATED GENES 1 $(N P R 1)$ is required for the jasmonate resistant 1 (jarl)-conferred enhanced disease resistance in inflorescence tissue

\begin{tabular}{lr}
\hline Genotype $^{\mathbf{a}}$ & \multicolumn{1}{c}{ FAD $^{\mathbf{b}}$} \\
\hline WT (Col) & $5.7 \pm 0.5$ \\
nprl & $12.9 \pm 1.2$ \\
jarl & $1.4 \pm 0.3$ \\
jarl nprl & $19.7 \pm 1.0$ \\
\hline
\end{tabular}

${ }^{\mathrm{a}} \mathrm{WT}=$ wild type.

${ }^{\mathrm{b}}$ Fusarium-Arabidopsis disease (FAD) value was evaluated at 7 days postinoculation.

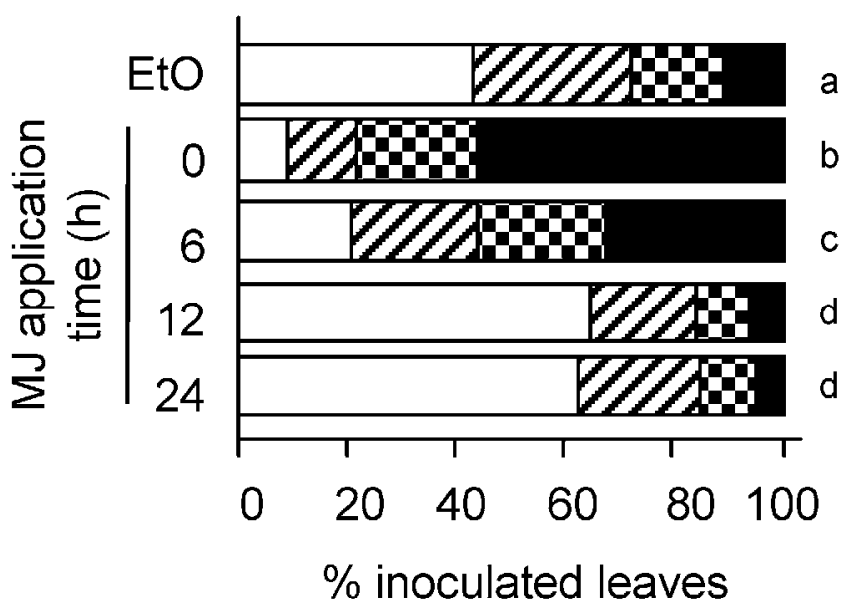

Fig. 7. Methyl-jasmonic acid (MJ) applied later during infection enhances resistance against Fusarium graminearum. F. graminearum disease severity in leaves of wild-type (WT) Arabidopsis Columbia exposed for $24 \mathrm{~h}$ to MJ vapors beginning at $0,6,12$, and 24 h postinoculation (hpi) with $F$. graminearum. Plants exposed to ethanol (EtO) vapors at 0 hpi provided the control. Disease severity was scored 4 days postinoculation. Fractions of inoculated leaves exhibiting necrosis covering $<25,25$ to 50,50 to 75 , and $>75 \%$ of the leaf area were determined for each treatment. Different letters to the right of each treatment indicate disease severities that are significantly different $(P<0.05)$ from each other. This experiment was repeated two times. 


\section{DISCUSSION}

Although $F$. graminearum is considered primarily a pathogen of cereal plants, it is also capable of causing disease in the dicotyledonous species Arabidopsis thaliana. Previously, Urban and associates (2002) showed that Arabidopsis flowers are susceptible to $F$. graminearum infection. Although the leaf surface provides a physical barrier to fungal penetration, $F$. graminearum can grow and cause disease when infiltrated into Arabidopsis leaves (Fig. 1A to C). This combination of leaf and inflorescence infection assays in Arabidopsis provides a powerful system for the molecular-genetic characterization of factors and mechanisms that govern resistance and susceptibility to $F$. graminearum. Experiments with Arabidopsis mutants defective in SA and JA signaling indicate that the genetic requirements for controlling disease severity are similar in the inflorescence tissues and leaves (Tables 1 and 2; Figs. 4A, 5C, and 6 ). These experiments demonstrate that SA signaling has an important role in controlling severity of $F$. graminearum disease, and JA signaling through JARl has two contrasting roles in this interaction.

The heightened susceptibility of the nprl mutant (Fig. 4A and B; Table 1) combined with the inability of SA and BTH to promote resistance against $F$. graminearum in the $n p r l$ mutant (Fig. 4B) indicates that, in Arabidopsis, the effect of SA on controlling $F$. graminearum growth is mediated through an NPR1-dependent mechanism. The heightened susceptibility of the wrkyl8 mutant and enhanced resistance of the WRKY18(OE) plant (Fig. 4A; Table 1) suggests that the WRKY18 arm of the NPRI-dependent mechanism contributes to this resistance. Similar to its interaction with $F$. graminearum, the SA-deficient sid 2 mutant is more susceptible than the WT to wilt disease caused by $F$. oxysporum and inflorescence infection by F. culmorum (Diener and Ausubel 2005; Cuzick et al. 2008). Moreover, NPRl is required for basal resistance to $F$. culmorum (Cuzick et al. 2008) and, in tomato, constitutive expression of NPRl enhanced resistance against $F$. oxysporum (Lin et al. 2004). Thus, SA signaling through NPRl is a mechanism that is engaged to control disease caused by a variety of Fusarium fungi.

Although necrotrophy coincides with increase in vigor of colonization by Fusarium spp., it is now an accepted fact that $F$. graminearum is a hemibiotroph that does not penetrate host cells during early stages of infection (Goswami and Kistler 2004). SA signaling could target this early stage of infection. Indeed, SA signaling was activated early during infection. Expression of $P R 1$, which is a molecular marker for the activation of SA signaling, was induced within $12 \mathrm{~h}$ of $F$. graminearum infection (Fig. 5A). PRI expression was detectable as early as 6 hpi. Furthermore, prior exposure to SA and BTH enhanced disease resistance (Fig. 4B). It is expected that the antifungal factors that target the fungus during this stage of the infection will be secreted outside the plant cell. In pathogeninfected plants, NPRI is required for the elevated expression of genes that encode proteins associated with the secretory machinery (Wang et al. 2005). These secretory pathway genes are required for the SAR-conferred enhanced resistance to pathogens, thus implying an important function for the secretory pathway in NPR1-orchestered resistance. Indeed, several of the PR proteins that are synthesized in pathogen-infected leaves accumulate in the extracellular spaces, and many of these proteins possess antifungal activities (Jayaraj et al. 2004). Furthermore, constitutive co-expression of two secreted PR proteins enhanced FHB resistance in transgenic wheat, and apoplastic fluids collected from these plants possessed an activity that was inhibitory to $F$. graminearum growth (Anand et al. 2004). SA signaling could also control disease progression during the necrotrophic phase of $F$. graminearum life cycle. There is precedence for SA's involvement in promoting resistance against necrotrophic fungi. SA accumulation was required for full resistance to B. cinerea and Plectosphaerella cucumerina (Thomma et al. 1998, 1999; Zimmerli et al. 2001; Berrocal-Lobo et al. 2002; Ferrari et al. 2003). Furthermore, in the case of B. cinerea, NPR 1 was required for the local restriction of pathogen growth by SA (Zimmerli et al. 2001; Ferrari et al. 2003).

Although JA signaling was activated in parallel with SA signaling in Arabidopsis leaves inoculated with $F$. graminearum (Fig. 5A), JA signaling promoted disease by constraining the activation of SA signaling through NPRl (Figs. 3A, 5E and F, and 6). The complete breakdown of NPRl(OE)-conferred heightened resistance when these plants were pretreated with MJ (Fig. 5B) supports this hypothesis. The higher content of SA in F. graminearum-inoculated opr 3 and jarl leaves compared with the WT leaves (Fig. 3A) suggests that JA most likely attenuates SA-mediated defenses by limiting SA accumulation in the $F$. graminearum-inoculated leaves. SA accumulation is similarly restricted by the activation of JA signaling in Arabidopsis and tomato infected with Pseudomonas syringae (Kunkel and Brooks 2002; Zhao et al. 2003; Uppalapati et al. 2007). Coronatine, a phytotoxin produced by $P$. syringae, mimics jasmonates and, thus, activates JA signaling in $P$. syringae-infected plants (Brooks et al. 2005; Zhao et al. 2003; Uppalapati et al. 2007). Mycotoxins produced by Fusarium spp. also activate expression of the JA-regulated PDF1.2 gene (Nishiuchi et al. 2006), and a recent study has suggested that $F$. oxysporum hijacks a COII-dependent mechanism to promote disease in Arabidopsis (Thatcher et al. 2009). Whether $F$. graminearum mycotoxins hijack host JA machinery for pathogenesis, similar to the function of coronatine in P. syringaeinfected plants, remains to be determined.

We have repeatedly observed that disease was more severe in the inflorescence and leaves of the jarl nprl double mutant than in the nprl single mutant (Table 2; Fig. 6). Although disease severity measurements were conducted at $4 \mathrm{dpi}$, most of jarl nprl double mutant plants had succumbed to infection by $3 \mathrm{dpi}$, which is a few days earlier than the nprl mutant. These results suggest that JARl contributes to overall resistance as well, although its contribution was masked in the presence of NPR1. In Arabidopsis, similarly, JARl is required for an NPRI-independent mechanism that contributes to basal resistance against the bacterial pathogen $P$. syringae (Clarke et al. 2000). Thus, although JA signaling through JARl suppresses SA- and NPRI-mediated defenses, a JARI-dependent mechanism also contributes to the control of fungal growth, presumably during later stages of infection. The ability of MJ to promote resistance when applied 12 to $24 \mathrm{~h}$ after fungal inoculation (Fig. 7) supports this hypothesis. Together, SA- and JA-dependent defenses could provide maximal protection against this fungus.

Although previous studies in which wheat heads were sprayed with BTH did not result in enhanced FHB resistance (Yu and Muehlbauer 2001), we have observed that irrigating wheat plants with SA and BTH effectively enhanced FHB resistance (R. Makandar and J. Shah, unpublished). Furthermore, FHB resistance was enhanced in transgenic wheat that accumulated elevated SA levels and constitutively expressed PR genes (Anand et al. 2003a and b). These observations, combined with the enhanced FHB resistance observed in wheat plants constitutively expressing Arabidopsis NPRI and the genetic evidence presented here confirming the importance of SA signaling in defense against $F$. graminearum in Arabidopsis inflorescence and leaves, advocates that the role of SA in wheat defense against $F$. graminearum needs to be reevaluated. Similarly, although MJ application was reported to con- 
trol severity of FHB in wheat (Li and Yen 2008), the role of JA signaling in wheat interaction with $F$. graminearum has not been genetically validated. Future experiments designed to discern the role of JA signaling in wheat interaction with $F$. graminearum should consider the results presented here on the dichotomous role of JA signaling in Arabidopsis interaction with $F$. graminearum, and the involvement of a JA-dependent mechanism as a susceptibility factor in Arabidopsis interaction with two other Fusarium fungi, F. oxysporum and F. culmorum (Cuzick et al. 2008; Thatcher et al. 2009).

\section{MATERIALS AND METHODS}

\section{Arabidopsis genotypes.}

The ssi2 mutant and the NahG transgenic (Shah et al. 1999, 2001) are in the A. thaliana accession Nössen and the sid2-2 (Wildermuth et al. 2001), cpr5 (Bowling et al. 1994), nprl-1 (Cao et al. 1994), jarl-1 (Staswick et al. 1998), wrkyl8 (Xu et al. 2006), and opr3 mutants; and the NPRl(OE) and WRKY18(OE) transgenic lines (Cao et al. 1998; Xu et al. 2006) are in the Arabidopsis accession Columbia. Arabidopsis plants were cultivated at $22^{\circ} \mathrm{C}$ in a growth chamber programmed for a cycle of $14 \mathrm{~h}$ of light $\left(100 \mu \mathrm{E} \mathrm{m}^{-2} \mathrm{~s}^{-1}\right)$ and $10 \mathrm{~h}$ of darkness. Approximately 4-week-old Arabidopsis plants were used for all experiments.

\section{Fungal cultivation and plant infections.}

$F$. graminearum isolate Z-3639 was cultured for 7 days on half-strength potato dextrose agar (Difco Laboratories, Detroit) at $22^{\circ} \mathrm{C}$. The fungus mass was then washed off the plate using a brush in $10 \mathrm{ml}$ of sterile distilled water and filtered through four layers of cheesecloth. The fungal suspension containing very short mycelial fragments $\left(30,000 \mathrm{ml}^{-1}\right)$ was infiltrated into the abaxial surface of Arabidopsis leaves with a needleless syringe. Four leaves per plant were infiltrated. Similarly processed washings collected from uninoculated plates were used for mock treatments. Infiltrated plants were covered with a clear plastic dome and disease severity recorded 4 dpi. The fraction of inoculated leaves exhibiting chlorosis covering $<25 \%$ (category 1), 25 to $50 \%$ (category 2), 50 to $75 \%$ (category 3 ), and $>75 \%$ (category 4 ) of leaf area were determined for each genotype. A minimum of 60 leaves from 15 plants of each genotype was analyzed for each experiment. Single-factor analysis of variance $(P<0.05)$ (v5.1; SAS, Cary, NC, U.S.A.) was used to compare disease severity among different genotypes and treatments.

For bioassays on Arabidopsis inflorescence, a hand atomizer was used to spray inoculate $F$. graminearum on plants that had bolts with open flowers on the terminal inflorescence and few developing siliques. Fungal suspension was applied until droplet run-off. Control plants were spray inoculated with water, and 15 to 20 plants from each genotype were inoculated with the fungus. After inoculation, plants were irrigated and covered individually with plastic separators to maintain high relative humidity. FAD value, which represents the combined disease severity on flowers, new siliques, and old siliques, was evaluated at $7 \mathrm{dpi}$, as previously described (Urban et al. 2002).

\section{Microscopic analysis of $\boldsymbol{F}$. graminearum in Arabidopsis leaves.}

Fungus-inoculated leaves were cut at the base and cleared with isopropanol. Cleared leaves were vacuum infiltrated $(2 \mathrm{~h}$ at $25 \mathrm{~mm} \mathrm{Hg}$ ) with a solution containing WGA-Alexa Fluor 488 (Invitrogen, Carlsbad, CA, U.S.A.) and Toluidine Blue-O supplemented with bovine serum albumin (New England Biolabs, Ipswich, MA, U.S.A.) in phosphate-buffered saline (PBS, $\mathrm{pH} 7.4)$, each at $10 \mu \mathrm{g} / \mathrm{ml}$. The leaves were then washed with
PBS and mounted using 30\% glycerol. The leaves were visualized under UV light with a Nikon Eclipse E600 (Lewisville, TX, U.S.A.) epifluorescent microscope equipped with a Sony (Park Ridge, NJ, U.S.A.) DSC-F707 camera and a triple excitation filter (excitation filter: 395 to 410,490 to 505, and 560 to 580 ; emission filter: 450 to 470,515 to 545 , and 600 to 650). The excitation wavelengths used for WGA-Alexa Fluor 488 and Toluidine Blue-O were between 395 to 410 and 490 to $505 \mathrm{~nm}$, respectively, with capture between 450 to 470 and 515 to $545 \mathrm{~nm}$, respectively.

\section{Induction of SAR.}

Biological activation of SAR was initiated by infiltrating three fully expanded Arabidopsis leaves with a suspension of the avirulent pathogen $P$. syringae pv. tomato DC3000 avrRpt2, as previously described (Chaturvedi et al. 2008). Plants infiltrated with $10 \mathrm{mM} \mathrm{MgCl}_{2}$ provided the mock controls. SAR was also activated by infiltrating three fully expanded Arabidopsis leaves with PeX collected from avirulent pathogenchallenged leaves. PeX collected from $10 \mathrm{mM} \mathrm{MgCl}_{2}$-infiltrated leaves provided the mock controls. PeX was collected as previously described by Chaturvedi and associates (2008). Three days after infiltration with avirulent bacteria or Avr PeX to activate SAR, three upper leaves of each plant were challenged with $F$. graminearum and disease rating evaluated 4 dpi, as described above.

\section{Chemical treatment of plants.}

SA and BTH treatments were carried out by subirrigating and spraying Arabidopsis plants to run-off with $200 \mu \mathrm{M}$ solutions of the chemicals or with water as a control. MJ treatment was accomplished by placing plants in a plexiglass chamber (48-liter volume) along with a cotton ball soaked with $1 \mathrm{ml}$ of $200 \mu \mathrm{M}$ MJ solution in $0.1 \%$ ethanol. Plants treated with ethanol $(0.1 \%)$, which was used to dissolve MJ, were used as a control for experiments with MJ.

\section{DNA extraction and polymerase chain reaction analysis.}

To extract DNA from fungus-infected leaves, Arabidopsis leaves showing different classes of disease symptoms were collected 6 dpi. Ten leaves per disease class were collected from four biological replicates and ground in liquid nitrogen using a mortar and pestle. Total DNA was extracted using the QIAGEN DNeasy plant mini kit (Qiagen, Hilden, Germany) according to the manufacturer's instructions. The cetyltrimethylammonium bromide (Leslie and Summerell 2006) method was used for extraction of fungal DNA from $F$. graminearum mycelia grown in potato dextrose broth. Hoechst dye 33258 (Sigma-Aldrich, St. Louis) was used for quantification of double-stranded DNA.

Genomic polymerase chain reaction (PCR) was used to detect the presence of fungus in plant tissue. Equal amounts of DNA (25 ng) from fungal-infected leaves were used for PCR analysis. The primers FgTri5-F (5'-AGCGACTACAGGCTTC CCTC-3') and FgTri5-R (5'-AAACCATCCAGTTCTCCATCT G-3'), designed to amplify the fungal Tri5-cluster (GenBank accession number AB060689), were used as a molecular probe to detect the presence of $F$. graminearum. These primers amplify a 486-bp fragment from the $F$. graminearum genome. The primers ACT8-1 (5'-ATGAAGATTAAGGTCGTGGCA$\left.3^{\prime}\right)$ and ACT8-2 (5'-TCCGAGTTTGAAGAGGCTAC-3'), derived from the Arabidopsis ACT8 (At1g49240) gene, were used as a control for the genomic PCR. These primers amplify a 450-bp fragment. PCR was performed using the following conditions: $95^{\circ} \mathrm{C}$ for $5 \mathrm{~min}$; followed by 40 cycles of $95^{\circ} \mathrm{C}$ for $30 \mathrm{~s}, 58^{\circ} \mathrm{C}$ for $45 \mathrm{~s}$, and $72^{\circ} \mathrm{C}$ for $1 \mathrm{~min}$; and a final extension at $72{ }^{\circ} \mathrm{C}$ for $5 \mathrm{~min}$. The PCR products were resolved on $2 \%$ 
agarose gel, stained with ethidium bromide, and visualized with a BioDoc-It system (UVP).

\section{RNA analysis.}

RNA from Arabidopsis leaves was extracted by a guanidinephenol method (Chomczynski and Sacchi 1987). For reversetranscription (RT)-PCR analysis, oligo(dT) primer (Promega Corp., Madison, WI, U.S.A.) was used for the RT reaction. RT reactions were carried out at $50^{\circ} \mathrm{C}$ for $30 \mathrm{~min}$ in $20-\mu \mathrm{lreac}$ tions with $100 \mathrm{ng}$ of total RNA as template. This cDNA $(1 \mu \mathrm{l})$ was utilized for the subsequent PCR step. The gene-specific primers PR1-F (5'-GCTCTTGTAGGTGCTCTTGTTC-3') and PR1-R (5' - CAGCTCTTATTTGTATTATTTG-3'), PDF1.2a-F (5'-TCATGGCTA AGTTTGCTTCC-3') and PDF1.2a- R (5'-A ATACACACGATTTAGCACC-3'), and ACT8-1 (5'-ATGAAG ATTAAGGTCGTGGCA-3') and ACT8-2 (5'-TCCGAGTTTG AAGAGGCT-3') were used for PCR amplification of the PRI (At2g14610), PDF1.2a (At5g44420), and ACT8 (At1g49240) cDNAs, respectively. The PCR amplifications were carried at $95^{\circ} \mathrm{C}$ for $5 \mathrm{~min}$; followed by 25 cycles of $95^{\circ} \mathrm{C}$ for $15 \mathrm{~s}, 56^{\circ} \mathrm{C}$ for $30 \mathrm{~s}$, and $72^{\circ} \mathrm{C}$ for $1 \mathrm{~min}$; with a final extension step of $72^{\circ} \mathrm{C}$ for $5 \mathrm{~min}$. For Northern blot analysis, $10 \mu \mathrm{g}$ of RNA was denatured and loaded on formaldehyde-agarose gels. RNA was transferred to Hybrid-N+ Nylon membrane (Amersham Biosciences, Piscataway, NJ, U.S.A.) and RNA blots were probed with the Arabidopsis PRI cDNA.

\section{SA quantification.}

A gas chromatography-mass spectrometry method, described by Schmelz and associates (2004), was adapted to quantify SA content in Arabidopsis leaves. Leaves (100 to $200 \mathrm{mg}$ fresh weight) were harvested and frozen immediately in liquid nitrogen. The frozen samples were ground with a pestle. Then, 300 $\mu \mathrm{l}$ of a 1-propanol/water/HCl (200:100:2) mix were added to the ground tissue, followed by vortexing. Next, $1 \mathrm{ml}$ of dichloromethane was added and, after mixing, the tubes were spun in a centrifuge to promote the separation of phases. The bottom phase containing extracted SA was transferred into a 4$\mathrm{ml}$ glass vial and SA content was quantified as previously described (Schmelz et al. 2004). To determine any SA-glucoside (SAG) that remained in the upper phase, the upper phase was transferred to a 4-ml glass vial that contained $1 \mathrm{ml}$ of dichloromethane. Dichloromethane was added to bring the volume to 2 ml. To hydrolyze the SAG to SA, $100 \mu$ l of concentrated $\mathrm{HCl}$ was added and the tubes. After vortexing, the tubes were heated at $96^{\circ} \mathrm{C}$ for $60 \mathrm{~min}$. The hydrolyzed samples were centrifuged and the bottom organic phase pipetted into a fresh vial. The upper phase was reextracted a second time with $1 \mathrm{ml}$ of dichloromethane. The lower organic phases (containing SA released from SAG) obtained from two rounds of extraction were combined, and the solvent was evaporated under $\mathrm{N}_{2}$ gas. High-performance liquid chromatography-grade methanol $(200 \mu \mathrm{l})$ was added and the contents were filtered through $0.22-\mu \mathrm{M}$ syringe-driven filters. Derivatization and quantification of SA was done as previously described (Schmelz et al. 2004). Total SA content in the samples was expressed as the sum of SA and SAG content.

\section{ACKNOWLEDGMENTS}

We thank F. Ausubel, J. Zhou, X. Dong, and Z. Chen for providing the nprl-1 jarl-1, opr3, NPRl(OE), and wrky18 and WRKY18(OE) seed, respectively. This material is based upon work supported by the United States Department of Agriculture under agreement number 59-0790-067. This is a cooperative project with the United States Wheat \& Barley Scab Initiative. Kansas Lipidomics Research Center was supported by National Science Foundation (EPS 0236913, MCB 0455318, DBI 0521587), Kansas Technology Enterprise Corporation, K-IDeA Networks of Biomedical
Research Excellence (INBRE) of the National Institute of Health (P20RR16475), and Kansas State University.

\section{LITERATURE CITED}

Agrios, G. N. 2005. Plant Pathology, 5th ed. Elsevier Academic Press, Amsterdam.

Anand, A. Schmelz, E. A., and Muthukrishnan, S. 2003a. Development of a lesion-mimic phenotype in a transgenic wheat line overexpressing genes for pathogenesis-related PR. proteins is dependent on salicylic acid concentration. Mol. Plant-Microbe Interact. 16:96-925.

Anand, A., Zhou, T., Trick, H. N., Gill, B. S., and Muthukrishnan, S. 2003b. Greenhouse and field testing of transgenic wheat plants stably expressing genes for thaumatin-like protein, chitinase and glucanase against Fusarium graminearum. J. Exp. Bot. 54:1001-1111.

Anand, A., Lei, Z., Summer, L. W., Mysore, K. S., Arakane, Y., Bockus, W. W., and Muthukrishnan, S. 2004. Apoplastic extracts from a transgenic wheat line exhibiting lesion-mimic phenotype have multiple pathogenesis-related proteins that are antifungal. Mol. Plant-Microbe Interact. 17:1306-1317.

Bai, G.-H., and Shaner, G. 2004. Management and resistance in wheat and barley to Fusarium head blight. Annu. Rev. Phytopathol. 4:135-161.

Berrocal-Lobo, M., Molina, A., and Solano, R. 2002.. Constitutive expression of ETHYLENE-RESPONSE-FACTOR1 in Arabidopsis confers resistance to several necrotrophic fungi. Plant J. 29:23-32.

Bowling, S. A., Guo, A., Cao, H., Gordon, A. S., Klessig D. F., and Dong, X. 1994. A mutation in Arabidopsis that leads to constitutive expression of systemic acquired resistance. Plant Cell 6:1845-1857.

Brooks, D. M., Bender, C. L., and Kunkel, B. N. 2005. The Pseudomonas syringae phytotoxin coronatine promotes virulence by overcoming salicylic acid-dependent defences in Arabidopsis thaliana. Mol. Plant Pathol. 6:629-639.

Cao, H., Bowling, S. A., Gordon, A. S., and Dong, X. 1994. Characterization of an Arabidopsis mutant that is nonresponsive to inducers of systemic acquired resistance. Plant Cell:6:1583-1592.

Cao, H., Li, X., and Dong, X. 1998. Generation of broad spectrum disease resistance by over expression of an essential regulatory gene in systemic acquired resistance. Proc. Natl. Acad. Sci. U.S.A. 95:6531-6536.

Chaturvedi, R., and Shah, J. 2007. Salicylic acid in plant disease resistance. Pages 335-370 in: Salicylic Acid-A Plant Hormone. S. Hayat and A. Ahmad, eds. Springer, Dordrecht, The Netherlands.

Chaturvedi, R., Krothapalli, K., Makandar, R., Nandi, A., Sparks, A., Roth, M., Welti, R., and Shah, J. 2008. Plastid $\omega-3$ desaturase-dependent accumulation of a systemic acquired resistance inducing activity in petiole exudates of Arabidopsis thaliana is independent of jasmonic acid. Plant J. 54:106-117.

Chen, C., and Chen, Z. 2002. Potentiation of developmentally regulated plant defense response by AtWRKY18, a pathogen-induced Arabidopsis transcription factor. Plant Physiol. 129:706-716.

Chen, X., Steed, A., Harden, C., and Nicholson, P. 2006. Characterization of Arabidopsis thaliana-Fusarium graminearum interactions and identification of variation in resistance among ecotypes. Mol. Plant Pathol. 7:391-403.

Chen, X., Steed, A., Travella, S. Keller, B., and Nicholson, P. 2009. Fusarium graminearum exploits ethylene signaling to colonize dicotyledonous and monocotyledonous plants. New Phytol. 182:975-983.

Chomczynski, P., and Sacchi, N. 1987.. Single-step method of RNA isolation by acid guanidium thiocyanate-phenol chloroform extraction. Anal. Biochem. 162:156-159.

Clarke, J. D., Volko, S. M., Ledford, H., Ausubel, F. M., and Dong, X. 2000. Roles of salicylic acid, jasmonic acid, and ethylene in cpr induced resistance in Arabidopsis. Plant Cell 12:2175-2190.

Cuzick, A., Lee, S., Gezan, S., and Hammond-Kosack, K. E. 2008. NPR1 and EDS11 contribute to host resistance against Fusarium culmorum in Arabidopsis buds and flowers. Mol. Plant Pathol. 9:697-704.

Delaney, T. P., Friedrich, L., and Ryals, J. A. 1995. Arabidopsis signal transduction mutant defective in chemically and biologically induced disease resistance. Proc. Natl. Acad. Sci. U.S.A. 92:6602-6606.

Diener, A. C., and Ausubel, F. M. 2005. RESISTANCE TO FUSARIUM OXYSPORUM 1, a dominant Arabidopsis disease-resistance gene, is not race specific. Genetics 171:305-321.

Durrant, W. E., and Dong, X. 2004. Systemic acquired resistance. Annu. Rev. Phytopathol. 42:185-209.

Ferrari, S., Plontikova, J. M., De Lorenzo, G., and Ausubel, F. M. 2003. Arabidopsis local resistance to Botrytis cinerea involves salicylic acid and camalexin and requires EDS4 and PAD2, but not SID2, EDS5 or PAD4. Plant J. 35:193-205.

Glazebrook, J. 2005. Contrasting mechanisms of defense against biotrophic and necrotrophic pathogens. Annu. Rev. Phytopathol. 43:205-227. 
Goswami, R. S., and Kistler, H. C. 2004. Heading for disaster: Fusarium graminearum on cereal crops. Mol. Plant Pathol. 5:515-525.

Jayaraj, J., Anand, A., and Muthukrishnan, S. 2004. Pathogenesis-related proteins and their roles in resistance to fungal pathogens. Pages 178205 in: Fungal Disease Resistance in Plants-Biochemistry, Molecular Biology and Genetic Engineering. Z. K. Punja, ed. Haworth Press, Binghamton, NY, U.S.A

Jing, H.-C., Anderson, L., Sturre, M. J. G., Hille, J., and Dijkwel, P. P. 2007. Arabidopsis CPR5 is a senescence-regulatory gene with pleiotropic functions as predicted by the evolutionary theory of senescence. J. Exp. Bot. 58:3885-3894

Kloek, A. P., Verbsky, M. L., Sharma, S. B., Schoelz, J. E., Vogel, J., Klessig, D. F., and Kunkel, B. N. 2001. Resistance to Pseudomonas syringae conferred by an Arabidopsis thaliana coronatine-insensitive (coil) mutation occurs through two distinct mechanisms. Plant J. 26:509-522.

Koornneef, A., and Pieterse, C. M. J. 2008. Cross talk in defense signaling. Plant Physiol. 146:839-844.

Kunkel, B. N., and Brooks, D. M. 2002. Cross talk between signaling pathways in plant defense. Curr. Opin. Plant Biol. 5:325-331.

Leslie, J. F., and Summerell, B. A. 2006. The Fusarium Laboratory Manual. Blackwell, Ames, IA, U.S.A.

Li, G., and Yen, Y. 2008. Jasmonate and ethylene signaling pathway may mediate Fusarium head blight resistance in wheat. Crop Sci. 48:18881896.

Lin, W.-C., Lu, C.-F., Wu, J.-W., Cheng, M.-L., Lin, Y.-M., Yang, N.-S., Black, L., Green, S. K., Wang, J.-F., and Cheng, C.-P. 2004. Transgenic tomato plants expressing the Arabidopsis NPR1 gene display enhanced resistance to a spectrum of fungal and bacterial diseases. Transgenic Res. 13:567-581.

Makandar, R., Essig, J. S., Schapaugh, M. A., Trick, H. N., and Shah, J. 2006. Genetically engineered resistance to Fusarium head blight in wheat by expression of Arabidopsis NPR1. Mol. Plant-Microbe Interact. 19:123-129.

Métraux, J.-P., Nawrath, C., and Genoud, T. 2002. Systemic acquired resistance. Euphytica 124:237-243.

Nishiuchi, T., Masuda, D., Nakashita, H., Ichimura, K., Shinozaki, K., Yoshida, S., Kimura, M., Yamaguchi. I., and Yamaguchi K. 2006. Fusarium phytotoxin trichothecenes have an elicitor-like activity in Arabidopsis thaliana, but its activity differed significantly among their molecular species. Mol. Plant-Microbe Interact. 19:512-520.

Pieterse, C. J. M., and van Loon, L. C. 2004. NPR1: the spider in the web of induced resistance signaling pathways. Curr. Opin. Plant Biol. 7:456464.

Pritsch, C., Vance, C. P., Bushnell, W. R., Somers, D. A., Hohn, T. M., and Muehlbauer, G. J. 2001. Systemic expression of defense response genes in wheat spikes as a response to Fusarium graminearum infection. Physiol. Mol. Plant Pathol. 58:1-12.

Reuber, T. L., Plotnikova, J. M., Dewdney, J., Rogers, E. E., Wood, W. and Ausubel, F. M. 1998. Correlation of defense gene induction defects with powdery mildew susceptibility in Arabidopsis enhanced disease susceptibility mutants. Plant J. 16:473-485.

Savitch, L. V., Subramaniam, R., Allard, G. C., and Singh, J. 2007. The GLK1 'regulon' encodes disease defense related proteins and confers resistance to Fusarium graminearum in Arabidopsis. Biochem. Biophys. Res. Commun. 359:234-238.

Schmelz, E. A., Engelberth, J., Tumlinson, J. H., Block, A., and Alborn, H. T. 2004. The use of vapor phase extraction in metabolic profiling of phyto hormones and other metabolites. Plant J. 39:790-808.

Shah, J., Tsui, F., and Klessig, D. F. 1997. Characterization of a salicylic acid-insensitive mutant (sail) of Arabidopsis thaliana, identified in a selective screen utilizing the SA-inducible expression of the tms 2 gene. Mol. Plant-Microbe Interact. 10:69-78.

Shah, J., Kachroo, P., and Klessig, D. F. 1999. The Arabidopsis ssil mutation restores pathogenesis-related gene expression in nprl plants and renders defensin gene expression salicylic acid dependent. Plant Cell 11:191-206.

Shah, J., Kachroo, P., Nandi, A., and Klessig, D. F. 2001. A recessive mutation in the Arabidopsis SSI2 gene confers SA- and NPR1-independent expression of $P R$ genes and resistance against bacterial and oomycete pathogens. Plant J. 25:563-574.

Skadsen, R. W., and Hohn, T. M. 2004. Use of Fusarium graminearum transformed with $g f p$ to follow infection patterns in barley and Arabidopsis. Physiol. Mol. Plant Pathol. 64:45-53.

Spoel, S. H., Koornneef, A., Chessens, S. M. C, Korzelius, J. P., VanPetl, J. A., Mueller, M. J., Buchala, A. J., Metaux, J.-P., Brown, R., Kazoan, K.
Van Loon, L. C., Dong, X., and Peiterse, C. M. J. 2003. NPR1 modulates cross- talk between salicylate and jasmonate dependent defense pathways through a novel function in the cytosol. Plant Cell 15:760-770.

Staswick, P. E., and Tiryaki, I. 2004. The oxylipin signal jasmonic acid is activated by an enzyme that conjugates it to isoleucine in Arabidopsis. Plant Cell 16:2117-2127.

Staswick, P. E., Yuen, G. Y., and Lehman, C. C. 1998. Jasmonate signaling mutants of Arabidopsis are susceptible to the soil fungus Pythium irregulare. Plant J. 15:747-754.

Thatcher, L. F., Manners, J. M., and Kazan, K. 2009. Fusarium oxysporum hijacks COI1-dependent jasmonate signaling to promote disease development in Arabidopsis. Plant J. 58:927-939.

Thomma, B. P. H. J, Eggermont, K., Penninckx, I., Mauch-Mani, B., Vogelsang, R., Cammue, B. P. A., and Broekaert, W. F. 1998. Separate jasmonate-dependent and salicylate-dependent defense-response pathways in Arabidopsis are essential for resistance to distinct microbial pathogens. Proc. Natl. Acad. Sci. U.S.A. 95:15107-15111.

Thomma, B. P. H. J, Eggermont, K., Tierens, K. F., and Broekaert, W. F 1999. Requirement of functional ethylene-insensitive 2 gene for efficient resistance of Arabidopsis to infection by Botrytis cinerea. Plant Physiol. 121:1093-1102.

Thomma, B. P. H. J., Eggermont, K., Broekaert, W. F., and Cammue, P. A. 2000. Disease development of several fungi on Arabidopsis can be reduced by treatment with methyl jasmonate. Plant Physiol. Biochem. 38:421-427.

Uppalapati, S. R., Ishiga, Y., Wangdi, T., Kunkel, B. N., Anand, A., Mysore, K. S., and Bender, C. L. 2007. The phytotoxin coronatine contributes to pathogen fitness and is required for suppression of salicylic acid accumulation in tomato inoculated with Pseudomonas syringae pv. tomato DC3000. Mol. Plant-Microbe Interact. 20:955-965.

Urban, M., Daniels, S., Mott, E., and Hammond-Kosack, K. 2002. Arabidopsis is susceptible to the cereal ear blight fungal pathogen Fusarium graminearum and Fusarium culomorum. Plant J. 32:961-973.

Van Hemelrijck, W., Wouters, P. F. W., Brouwer, M., Windelinckx, A., Goderis, I. J. W. M., De Bolle, M. F. C., Thomma, B. P. H. J., Cammue, B. P. A., and Delaure, S. L. 2006. The Arabidopsis defense response mutant esa1 as a model to discover novel resistance traits against Fusarium diseases. Plant Sci. 171:585-595.

van Loon, L. C., Rep, M., and Pieterse, C. M. J. 2006. Significance of inducible defense-related proteins in infected plants. Annu. Rev. Phytopathol. 44:135-162.

Walter, S., Nicholson, P., and Doohan, F. M. 2010. Action and reaction of host and pathogen during Fusarium head blight disease. New Phytol. 185:54-66.

Wang, D., Weaver, N. D., Kesarwani, M., and Dong, X. 2005. Induction of protein secretory pathway is required for systemic acquired resistance. Science 308:1036-1040.

Wang, D., Amornsiripanitch, N., and Dong, X. 2006. A genomic approach to identify regulatory nodes in the transcriptional network of systemic acquired resistance in plants. PLoS Pathogens 2:1042-1050.

Wasternack, C. 2007. Jasmonates: an update on biosynthesis, signal transduction and action in plant stress response, growth and development. Ann. Bot. 100:681-697.

Wildermuth, M. C., Dewdney, J., Wu, G., and Ausubel, F. M. 2001. Isochorismate synthase is required to synthesize acid for plant defense. Nature 414:562-565

Xu, X., Chen, C., Fan, B., and Chen, Z. 2006. Physical and functional interactions between pathogen-induced Arabidopsis WRKY18, WRKY40, and WRKY60 transcription factors. Plant Cell 18:1310-1326.

Yu, G.-Y., and Muehlbauer, G. J. 2001. Benzothiadiazole-induced gene expression in wheat spikes does not provide resistance to Fusarium head blight. Physiol. Mol. Plant Pathol. 59:129-136.

Zhao, Y., Thilmony, R., Bender, C. L., Schaller, A., He, S. Y., and Howe, G. A. 2003. Virulence systems of Pseudomonas syringae pv. tomato promote bacterial speck disease in tomato by targeting the jasmonate signaling pathway. Plant J. 36:485-499.

Zimmerli, L., Métraux, J.-P., and Macuh-Mani, B. 2001. $\beta$-Aminobutyric acid-induced protection of Arabidopsis against the necrotrophic fungus Botrytis cinerea. Plant Physiol. 126:517-523.

\section{AUTHOR-RECOMMENDED INTERNET RESOURCES}

SAS website: www.sas.com

Promega Corp. website: www.promega.com

Amersham Biosciences website: www.amersham.com 